
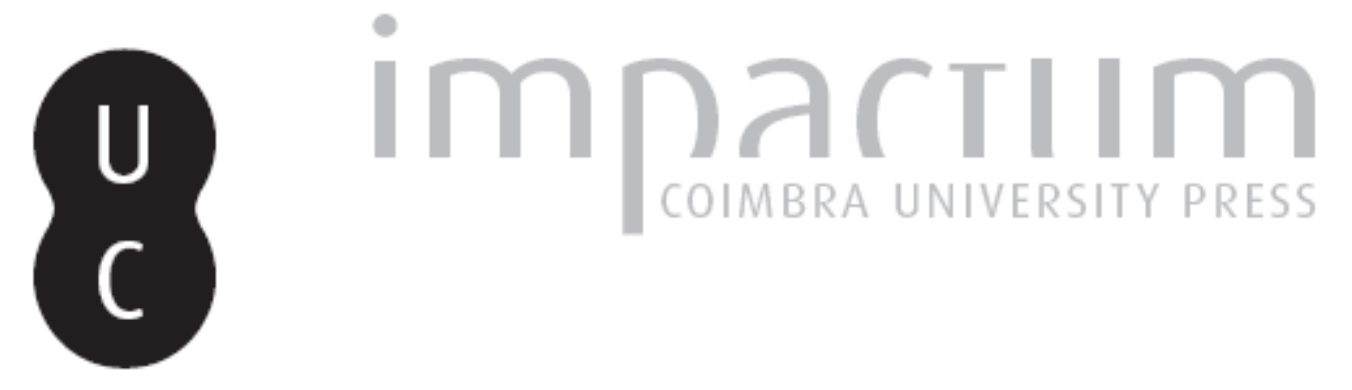

\title{
Fundamentos da mensagem moral dos profetas bíblicos
}

Autor(es): $\quad$ Gonçalves, Francolino J.

Publicado por: Centro de História da Universidade de Lisboa

URL persistente:

URI:http://hdl.handle.net/10316.2/23826

DOI:

DOI:http://dx.doi.org/10.14195/0871-9527_18_1

Accessed : $\quad$ 26-Apr-2023 12:32:11

A navegação consulta e descarregamento dos títulos inseridos nas Bibliotecas Digitais UC Digitalis, UC Pombalina e UC Impactum, pressupõem a aceitação plena e sem reservas dos Termos e Condições de Uso destas Bibliotecas Digitais, disponíveis em https://digitalis.uc.pt/pt-pt/termos.

Conforme exposto nos referidos Termos e Condições de Uso, o descarregamento de títulos de acesso restrito requer uma licença válida de autorização devendo o utilizador aceder ao(s) documento(s) a partir de um endereço de IP da instituição detentora da supramencionada licença.

Ao utilizador é apenas permitido o descarregamento para uso pessoal, pelo que o emprego do(s) título(s) descarregado(s) para outro fim, designadamente comercial, carece de autorização do respetivo autor ou editor da obra.

Na medida em que todas as obras da UC Digitalis se encontram protegidas pelo Código do Direito de Autor e Direitos Conexos e demais legislação aplicável, toda a cópia, parcial ou total, deste documento, nos casos em que é legalmente admitida, deverá conter ou fazer-se acompanhar por este aviso.

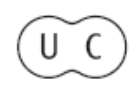



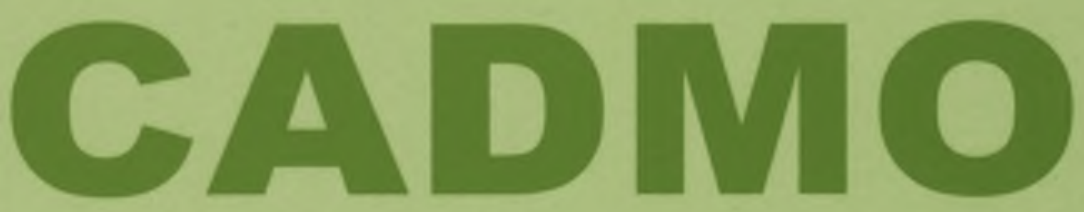

Revista de História Antiga

\author{
Centro de História \\ da Universidade de Lisboa
}

18

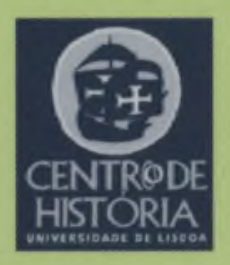

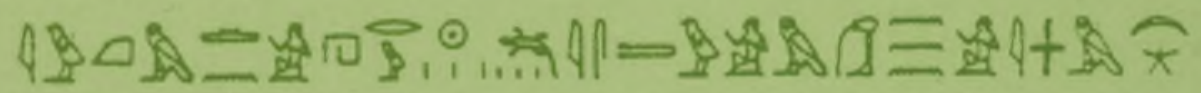

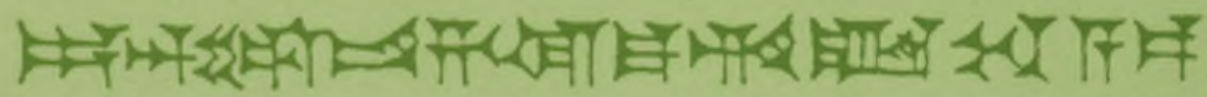

MHNIN AEI $\Delta$ E $\Theta E A ~ \Pi H \Lambda H I A \triangle E \Omega$ 


\title{
FUNDAMENTOS DA MENSAGEM MORAL DOS PROFETAS BÍBLICOS
}

\author{
FRANCOLINO J. GONÇALVES \\ École Biblique et Archéologique Française, Jerusalém \\ francolino@gmail.com
}

\section{Sommaire}

Tous les prophètes bibliques tiennent Yahvé pour l'auteur des normes morales, celui qui les fait connaître et veille à leur observance. Cet article a pour objectif de montrer que, en revanche, ils divergent au sujet du lieu, ainsi que des bénéficiaires, de la révélation de ces normes. Pour les uns, Yahvé les révèle au moyen de la création; elles sont donc universelles. Pour les autres, Yahvé révèle ses lois directement et uniquement à Israël et/ou à Juda, les seuls à qui elles s'appliquent. Ces deux systèmes moraux font partie de deux formes de yahvisme différentes, fondées l'une sur le mythe de la création et l'autre sur l'histoire des rapports entre Yahvé et son peuple «Israël».

\section{Summary}

All the biblical prophets hold that Yahweh is the author of moral norms, the one who makes them known and watches over their observance. This article has the objective of showing that, nevertheless, they diverge on the subject of the place as well the beneficiaries of the revelation of these norms. For some, Yahweh reveals them through creation; they are thus universal. For others, Yahweh reveals his laws directly and uniquely to Israel and/or Judah, to whom they apply. These two moral systems are part of two forms of Yahwism, one founded on the myth of creation, the other on the history of the relation of Yahweh and his people, «lsrael». 
A denúncia das injustiças e o anúncio dos infortúnios que elas atrairão são traços característicos dos porta-vozes de lavé dos séculos VIII e VII a. C., cada um dos quais deu o nome a um livro profético. Essas personagens não eram profetas ( $\left.n^{e} b i^{\wedge} i ̂ m\right)$ nem aos seus próprios olhos nem aos olhos dos contemporâneos. Pelo contrário, eram concorrentes dos profetas e seus adversários. Apesar disso, a tradição fez deles os profetas por excelência ${ }^{(1)}$. Com a tradição, apelidá-los-ei de profetas, por comodidade.

A mensagem moral dos profetas foi estudada amiúde no contexto das investigações sobre o Antigo Testamento em geral, o conjunto dos profetas, abrangendo um grupo entre eles ou um profeta determinado. A minha atenção vai incidir só nos titulares dos livros proféticos que exerceram a sua actividade entre meados do século VIII e os começos do século $\mathrm{VI}$ a. C., limitando-me a perguntar: em nome de que critérios consideraram maus determinados comportamentos ou práticas e anunciaram que teriam consequências catastróficas? Os especialistas do Antigo Testamento deram a esta pergunta numerosas respostas, de que seria difícil fazer o elenco completo ${ }^{(2)}$. Sob pena de simplificar demasiado, classifico-as em dois grupos, que pressupõem duas concepções diferentes do papel desempenhado pelos profetas na história do iaveísmo e correspondem a dois períodos no estudo dessas personagens.

A maioria dos estudiosos entre meados do século XIX e meados do século $\mathrm{XX}$ pensava que os profetas, sobretudo os do século VIII a. C., fundavam a sua mensagem moral no "monoteísmo ético", que seria obra deles e constituiria a verdadeira religião de Israel ${ }^{(3)}$. Esta concepção do papel dos profetas pressupõe a ruptura com a tradição que via no Pentateuco (Lei/Tôrāh, na terminologia judaica) a parte mais antiga da Bíblia e o ponto de partida da sua religião(4). A inversão na ordem cronológica entre a Lei e os Profetas foi um dos principais resultados dos estudos histórico-críticos da segunda metade do século XIX. É verdade que, no estado actual dos estudos vetero-testamentários, os discursos de Amós, Oseias, Isaías e Miqueias são os textos bíblicos mais antigos que se podem datar com uma certeza razoável. Isso não implica, no entanto, que essas personagens tenham sido os fundadores da religião bíblica. Pelo contrário, a análise dos seus discursos mostra que eles são, de facto, herdeiros de tradições anteriores, nas quais se enraízam. Com a maioria dos exegetas actuais, penso que foi nessas tradições que os profetas fundaram as suas mensagens morais. Entre as suas fontes de inspiração pensa-se 
sobretudo no direito, mas também na sabedoria e nas normas de conduta que ela formulou.

Os estudos consagrados à questão consideram os profetas como se eles formassem uma corporação homogénea, que teria existido no reino de Israel, no reino de Judá e na Judeia durante vários séculos. Os estudiosos não têm em conta o facto de que o Antigo Testamento qualifica de profetas personagens muito diferentes umas das outras, às quais atribui actividades diversas. Restringindo-me aos titulares dos livros proféticos, proponho-me demonstrar que não fazem todos apelo aos mesmos critérios para declarar bons ou maus determinados comportamentos ou práticas. Uns referem-se a normas de conduta que qualquer ser humano pode induzir a partir da criação, obra de lavé, e que são válidas para todos os seres humanos e para todos os povos. Os outros invocam leis positivas que lavé ditou directa e exclusivamente a Israel ou a Judá e que só a eles se aplicam. Amós e Isaías são excelentes representantes do primeiro grupo, Oseias e Jeremias do segundo. Tomá-los-ei como amostras. O estudo de Amós e Isaías, com que começarei, será o mais longo. A sua achega parece-me ser também a mais inovadora. Prolongando as conclusões do estudo, esboçarei as duas formas do iaveísmo de que as duas "morais" são a expressão.

\section{Amós e Isaías}

Amós exerceu a sua actividade no reino de Israel em meados do século VIII a. C. Um pouco posterior, Isaías exerceu a sua no reino de Judá na segunda metade desse mesmo século. Existem semelhanças óbvias entre os oráculos de Amós e os de Isaías, tanto do ponto de vista da forma como do conteúdo. São particularmente flagrantes no que respeita às suas mensagens morais. Ambos denunciam, ao mesmo tempo, as injustiças de Israel e/ou de Judá e as injustiças de um ou mais povos estrangeiros, e anunciam os infortúnios que elas thes valerão. Servem-se para isso das mesmas formas literárias e expressam tanto as denúncias como os anúncios em termos muito próximos. Vou passar revista às suas denúncias, primeiro, das nações estrangeiras e, depois, de Israel e/ou de Judá, procurando determinar em nome de que critérios as fazem. 


\section{As injustiças das nações estrangeiras}

\section{a) Amós}

Como a maioria dos livros proféticos, Amós contém oráculos contra várias nações estrangeiras. No entanto, o livro de Amós afastase da prática corrente em dois pontos importantes. Contrariamente à maioria dos livros, que situam os oráculos contra as nações estrangeiras no centro e os separam dos oráculos contra Israel e/ou Judá(5), Amós põe-os no começo e junta-os com oráculos contra Judá e Israel. Com efeito, Am 1,3-2,16* começa com seis povos estrangeiros e termina com Judá e Israel. Os oráculos têm todos a mesma estrutura, sendo uma espécie de formulário preenchido com os nomes dos diferentes povos, os respectivos pecados e castigos $^{(6)}$. Juntando Israel e Judá com as nações estrangeiras na mesma colectânea de oráculos e utilizando o mesmo formulário para tratar duns e doutras, o livro de Amós põe Israel, Judá e as nações estrangeiras em pé de igualdade. Razões de forma e de conteúdo, nomeadamente referências a acontecimentos muito posteriores a Amós, levam a ver nos oráculos contra Tiro e a Fenícia (1,9-10), Edom (1,11-12) e Judá $(2,4-5)$ acrescentos ulteriores. A colectânea primitiva constaria de cinco oráculos visando Damasco (1,3-5), Gaza e a Filisteia (1,6-8), Amon (1,13-15), Moab $(2,1-3)$ e Israel $\left(2,6-16^{\star}\right)$.

Os pecados que Amós imputa aos povos estrangeiros situam-se no domínio das relações internacionais e têm por quadro hostilidades militares $^{(7)}$. Trata-se de atrocidades que hoje se chamariam crimes de guerra ou crimes contra a humanidade: Damasco esmagou Galaad com trilhos de ferro $(1,3)^{(8)}$, Gaza deportou populações inteiras $(1,6)$, Amon esventrou as mulheres grávidas ${ }^{(9)}$ de Galaad para aumentar o seu território $(1,13)$ e Moab queimou os ossos do rei de Edom $(2,1)$. Os autores dos crimes são cada um dos povos visados, tomado colectivamente. As suas vítimas são estrangeiras: toda a população, uma parte dela, o próprio rei.

Dado que não se conhece bem a história das nações mencionadas, tanto a das criminosas como a das vítimas, é difícil saber a que acontecimentos os textos se referem. Além disso, o carácter estereotipado da evocação dos crimes de um ou outro povo, e mais ainda do anúncio da sua ruína, acresce a dificuldade. Tendo estado Galaad sob soberania ora israelita ora damascena, poderia pensar-se que Amós condena as atrocidades de Damasco e de Amon por terem tido 
Israelitas por vítimas. Como o oráculo contra Gaza não identifica as populações deportadas $(1,6)$, não se pode excluir com certeza absoluta que elas fossem Israelitas. Pelo contrário, a profanação dos ossos do rei de Edom por Moab $(2,1)$ não tem certamente nada a ver com Israel. Pode, portanto, excluir-se que Amós a condene por razões nacionalistas.

A condenação das nações estrangeiras assenta nos seguintes pressupostos: a) uma concepção moral de lavé e das relações entre ele e todos os povos; b) a existência de normas de conduta nas relações internacionais que todos os povos devem conhecer e com as quais têm de conformar-se; c) lavé mede o comportamento de todos os povos pela bitola dessas normas. Entre as questões que suscitam estes pressupostos, duas parecem-me particularmente pertinentes para o nosso propósito. Uma é a seguinte: como conheciam todos os povos as normas morais universais? Os oráculos de Amós não dão uma resposta explícita a esta questão. No entanto, nada sugere que lavé tenha revelado directamente essas normas aos povos estrangeiros nem que eles as conhecessem graças a Israel. De facto, nenhum dos crimes denunciados em Am 1,3-2,3* consta nas leis do Antigo Testamento. Estreitamente ligada ao modo do conhecimento das normas, há também a questão do seu fundamento e da fonte da sua autoridade. Os oráculos de Amós não deixam qualquer dúvida de que lavé vela pelo respeito das ditas normas. No entanto, não dizem explicitamente que lavé é também o seu autor e a fonte da sua autoridade. Mas, no contexto bíblico, quem poderia sê-lo senão ele? O mais simples é, sem dúvida alguma, pensar que lavé vela pela observância das normas morais universais porque ele é o seu autor. Ora a acção de lavé que concerne todos os povos é a criação. Por isso é legítimo supor que as ditas normas têm a criação como fundamento.

\section{b) Isaías}

Embora não seja o correspondente exacto de Am 1,3-2,16*, Is 10,5-15* tem semelhanças muito estreitas com essa colectânea. Servindo-se do mesmo formulário para vários povos estrangeiros e Israel, Is $10,5-15^{\star}$ usa para a Assíria o oráculo introduzido pela interjeição fúnebre "ai!» (hôy), uma forma literária que Isaías emprega amiúde, para anunciar a ruína de Judá(10), de Jerusalém (Is 29,1) e de Israel (Is 28,1$)^{(11)}$. Como Am 1,3-2,16* visa ao mesmo tempo vários povos estrangeiros e Israel, Is $10,5-15^{\star}$ trata ao mesmo tempo dum grande 
infortúnio de Judá e da ruína da Assíria. A razão da ruína da Assíria está ligada à missão de punir Judá que lavé lhe confiou (Is 10,5-6). Consiste, precisamente, no facto de que a Assíria se recusou a ser agente de lavé. Rejeitando a soberania de lavé e reivindicando a sua total independência, a Assíria pretende agir por sua própria iniciativa, ter o seu próprio plano (Is 10,7 ) e realizá-lo mediante a sua própria força e a sua própria sabedoria (Is 10,8-9.13-14). Ora o plano da Assíria consiste em suprimir nações em grande número (Is 10,7b) e em abolir as fronteiras dos povos (Is 10,13b). Como os crimes das nações estrangeiras em Am $1,3-2-3^{\star}$, os crimes da Assíria, em Is 10,5-15*, situam-se, assim, no quadro das relações internacionais e têm por contexto as hostilidades militares. O plano da Assíria e as proezas de que ela se vangloria equivalem, de facto, a desfazer a obra de lavé, que repartiu a humanidade em nações e lhes estabeleceu as fronteiras ${ }^{(12)}$. O alargamento das fronteiras de que Am 1,13 acusa Amon deve ter igualmente como pano de fundo o mito da repartição primordial da humanidade em nações, cada qual com o seu

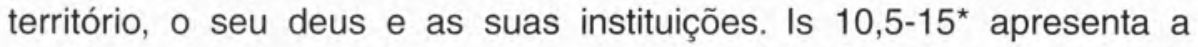
Assíria como rival de lavé e uma espécie de anti-lavé, que pretende apropriar-se do que só pode ser um privilégio de lavé. É nisso que reside o pecado da Assíria e a razão da sua ruína, que Isaías anuncia de maneira dramática, imitando de antemão o seu funeral.

\section{As injustiças de Israel e de Judá}

Enquanto os oráculos de Amós e de Isaías contra as nações estrangeiras têm como quadro as relações internacionais e denunciam crimes cometidos por essas nações umas contra as outras, os seus oráculos de carácter moral contra Israel e Judá têm como quadro a política interna desses dois reinos, denunciando injustiças cometidas no seu seio que têm como autores os poderosos e como vítimas o resto da população. Os infortúnios que essas injustiças vão causar atingirão não só os poderosos, os fautores das injustiças, mas o conjunto de Israel ou de Judá. Os pobres e os indefesos são, assim, duplamente vítimas: da injustiça dos poderosos e, curiosamente também, do infortúnio que as injustiças dos mesmos poderosos provocarão.

Várias das práticas denunciadas por Amós e Isaías são objecto de leis positivas que se encontram nos códigos bíblicos: o assassínio ${ }^{(13)}$, a escravatura por dívida ${ }^{(14)}$, o roubo ${ }^{(15)}$, os pesos e as medidas 
falsos ${ }^{(16)}$, a retenção das vestes penhoradas ${ }^{(17)}$, a corrupção da justiça ${ }^{(18)}$, a opressão das viúvas e dos órfãos ${ }^{(19)}$. Sendo homens cultos, Amós e Isaías conheciam certamente as leis que regiam Israel e Judá, mas não citam nenhuma delas e nada indica que se abrigavam sob a autoridade de qualquer lei positiva. Quando as suas denúncias das injustiças coincidem com o objecto duma lei documentada no Antigo Testamento, Amós e Isaías dão mostras duma exigência moral muito maior. É, por exemplo, o caso da condenação amosiana da escravatura por dívida ou, pelo menos, por uma dívida insignificante (Am 2,6 e 8,6). É também o caso da condenação isaiana da confiscação pelos credores ricos dos bens - casas e campos - dos pobres insolventes (Is 5,8-10). Dito isto, muitas das práticas que Amós e Isaías denunciam não estavam previstas por nenhuma lei(20). É o caso do luxo, dos banquetes, das bebedeiras, da arrogância dos ricos ${ }^{(21)}$, da "coquetterie" das damas de Jerusalém (Is 3,16-4,1*), da opressão dos pobres em geral (Am 2,7; 8,4). Também não se conhece nenhuma lei que impusesse a prática da justiça como condição para poder celebrar o culto(22). Tampouco se conhece uma lei que proibisse Xebná, administrador do palácio real, de mandar talhar no rochedo um sepulcro sumptuoso (Is 22, 15-19). Aparentemente, Isaías condena a acção de Xebná por ele ser um novo-rico, sem linhagem em Jerusalém. Não há dúvida de que Amós e Isaías intervêm sobretudo em domínios que estão fora da alçada da lei. As suas denúncias têm os paralelos mais próximos nas partes mais antigas do livro dos Provérbios. Limito-me a algumas das práticas denunciadas por Amós e Isaías que estão fora do âmbito da lei.

\section{a) O luxo, os banquetes, as bebedeiras e a arrogância}

Começo pelo luxo, pelos banquetes, as bebedeiras e a arrogância, práticas denunciadas por Amós e Isaías, em termos semelhantes. Tomo a Isaías como referência ${ }^{(23)}$. Ao fio do texto, a primeira passagem pertinente é Is $5,11-13$ :

" 11 Ai! Os que madrugam correndo à bebida inebriante

e até ao crepúsculo o vinho os inflama.

${ }^{12}$ São só cítaras e harpas,

pandeiretas e flautas, e vinho nos seus banquetes,

e não reparam na acção de lavé,

nem vêem a obra das suas mãos. 
${ }^{13}$ Por isso é exilado o meu povo, por falta de conhecimento.

Os seus notáveis, uns famintos,

E a sua plebe ressequida pela sede."

O abuso das bebidas inebriantes torna o homem incapaz de prestar atenção à obra de lavé e de a discernir. Is 5,11-13 diz acerca da relação entre o homem e a obra de lavé o que $\operatorname{Pr} 20,1$ diz da relação entre o homem e a sabedoria:

«Arrogante é o vinho, tumultuosa é a bebida inebriante!

Quem se perde neles não se tornará sábio.”

Por maioria de razão, o abuso das bebidas inebriantes torna os sacerdotes e os profetas incapazes de exercerem as suas funções docentes. É o que ilustra Is 28,7-13, o outro texto do Antigo Testamento que emprega, como $\operatorname{Pr} 20,1$, a expressão «perder-se no vinho» ${ }^{(24)}$. Cito só Is 28, 7-9:

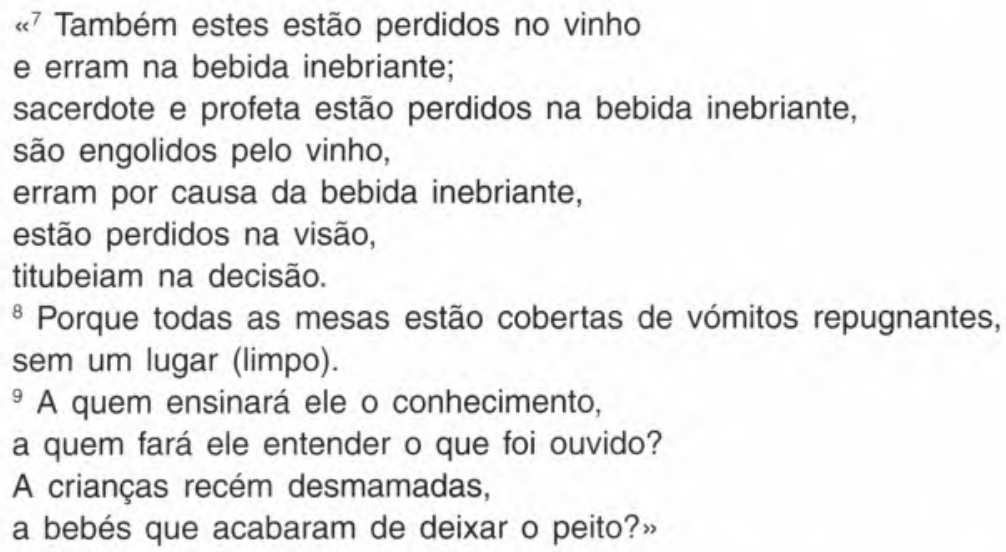

Este texto denuncia as bebedeiras dos sacerdotes e dos profetas e evoca os efeitos nefastos que têm para o exercício das suas funções ${ }^{(25)}$. A cena deve ter por quadro o templo de Jerusalém e situar-se no contexto do exercício das funções tanto dos sacerdotes como dos profetas. Ez 44,21 e Lv 10,9-11, textos que são muito posteriores a Is $28,7-13$, proíbem o uso do vinho pelos sacerdotes no exercício das suas funções ${ }^{(26)}$. A proibição da prática é a prova de que ela existiu. Há outros indícios na Bíblia de que o consumo de bebidas alcoólicas era um dos meios a que se recorria para provocar a revelação divina $^{(27)}$, mas não se conhece nenhuma lei que proíba essa prática. 
O extravio no vinho impede qualquer ser humano de se tornar sábio, segundo $\operatorname{Pr} 20,1$; impede os sacerdotes e os profetas de reconhecerem a palavra de lavé, transmitida por Isaías. Confiados nas suas prerrogativas de profissionais do ensino, os sacerdotes e os profetas consideram infantil essa palavra, fazem troça dela e rejeitam-na. Por isso, da boca dos sacerdotes e dos profetas bêbedos, em vez do ensino e das decisões justas que se esperam, só saem vómitos. Is 28,7-9 não é o único texto de Isaías que associa a arrogância e o orgulho ao abuso do vinho. Is 28,1 faz outro tanto em relação aos governantes de Samaria. Por sua vez, Is 5,22-23 declara que o abuso da bebida corrompe a administração da justiça. Nos Provérbios, como nos livros de Amós e de Isaías, o abuso das bebidas alcoólicas anda, assim, associado ao luxo, à arrogância, ao orgulho e à vaidade, que incapacitam para aceder à sabedoria, para apreender a obra ou a palavra de lavé e, por maioria de razão, para exercer as funções de ensino e de governo.

Os autores dos Provérbios e os sábios em geral polemizam contra o abuso das bebidas alcoólicas em nome da experiência. Privando os seres humanos de lucidez e do sentido da medida, o abuso das bebidas alcoólicas torna-os incapazes de se comportarem de maneira razoável. Por maioria de razão, torna os dirigentes incapazes de dirigir: os guias de guiar, os governantes de governar, os juízes de administrar a justiça. $\operatorname{Pr} 31,4-5$ expressa essa ideia de maneira particularmente incisiva:

${ }^{4}$ Não convém aos reis, Lemuel, não convém aos reis beber vinho, nem aos governantes (beber) bebida inebriante;

${ }^{5}$ para que não suceda que, bebendo, esqueçam o que está estatuído e pervertam o direito de todos os infelizes".

Para os sábios, não há qualquer dúvida de que as conclusões da experiência humana correspondem à ordem do mundo instaurada por lavé. A sobriedade não é uma simples receita para ter êxito na vida; ela faz parte da criação. Tal deve ser também a concepção de Amós e de Isaías.

\section{b) $O$ culto sem justiça}

Amós e Isaías denunciam o culto sem justiça. Essa denúncia é particularmente insistente na boca de Amós. Veja-se Am 5,21-24:

" ${ }^{21}$ Odeio, desprezo as vossas festas

e não gosto das vossas assembleias. 
${ }^{22}$ Se me ofereceis holocaustos...

As vossas oblações não me aprazem.

Não olho para o sacrifício dos vossos animais cevados.

${ }^{23}$ Afasta de mim o ruído dos teus cânticos,

que eu não ouça a música das tuas harpas!

24 Mas que o direito escorra como água,

e a justiça, como uma torrente perene."

As condenações amosianas e isaianas do culto sem justiça ou, pior ainda, do culto que põe a injustiça ao seu serviço têm os paralelos mais estreitos nos Provérbios. Assim, lê-se em $\operatorname{Pr} 15,8$ :

"O sacrifício dos maus é uma abominação para lavé, mas a oração dos homens rectos faz as suas delícias."

De modo semelhante, $\operatorname{Pr} 21,3$ reza assim:

«Praticar a justiça e o direito

vale, para lavé, mais do que o sacrifício."

\section{c) A opressão dos pobres em geral}

As denúncias da opressão dos pobres ocupam um lugar muito importante tanto em Amós como em Isaías. É verdade que Dt 24,14 proíbe a exploração do assalariado, qualificado de humilde ('ānî) e de pobre ('èbeyôn). No entanto, não se conhece nenhuma lei que proíba a opressão dos pobres em geral. As denúncias de Amós e de Isaías nesta matéria têm os paralelos mais estreitos nas numerosas declarações dos Provérbios relativas à conduta a seguir para com os pobres. Assim, lê-se em $\operatorname{Pr} 14,31$ :

"Quem oprime o indigente ultraja aquele que o fez, mas quem tem compaixão do pobre honra-o."

O Criador identifica-se com o pobre porque ele é sua criatura. Deus identifica-se com a sua obra. A bondade com que se deve agir para com os pobres funda-se, por conseguinte, na obra criadora de Deus. Pr 17,5 acrescenta que quem faz troça do pobre não o fará impunemente. Pelo contrário, $\operatorname{Pr} 19,17$ declara:

"Quem tem compaixão do fraco empresta a lavé, que Ihe retribuirá o benefício." 


\section{d) Amós e Isaías fundam a moral na criação}

Amós e Isaías não julgam Israel e Judá em nome das suas leis positivas. Medem-nos com outras normas, que são muito mais exigentes e se estendem a um leque de comportamentos e de práticas bem mais amplo. Dadas as suas afinidades estreitas com os Provérbios, pode concluir-se que, como eles, Amós e Isaías julgam a sociedade israelita e judaica em nome de normas fundadas na criação. Aos olhos de Amós e de Isaías, não se conformar com essas normas equivale a pretender substituir a criação de lavé por outra. É o que ressalta de Am 6,12:

«Porventura correm cavalos sobre o rochedo, lavra-se o rochedo (ou o mar ${ }^{(28)}$ ) com bois? para fazerdes do direito veneno, do fruto da justiça absinto?»

Am 6,12a formula duas perguntas retóricas, de estilo sapiencial. Sendo formuladas na afirmativa, as perguntas exigem respostas negativas, consideradas como óbvias. São relativas a duas acções absurdas. Não é, evidentemente, da natureza das coisas que os cavalos corram sobre o rochedo ou que se lavre o rochedo ou o mar com bois. De igual modo, é contra a natureza das coisas que os Israelitas transformem o direito e a justiça em veneno e em absinto. Fazendo isso, eles subvertem a ordem do mundo estabelecida por lavé. Am 5,7 expressa a mesma ideia praticamente nos mesmos termos. A mesma ideia, expressa igualmente com o verbo revirar/subverter (hāpak) e por meio de duas perguntas retóricas, lê-se também em Is 29,16 . No mesmo sentido, cito Is 5,20 :

"Ai! Os que declaram o mal bem e o bem mal,

os que substituem as trevas pela luz e a luz pelas trevas,

os que substituem o amargo pelo doce e o doce pelo amargo."

O estudo dos oráculos de Amós e de Isaías contra Israel e Judá confirma, fundamenta e esclarece as conclusões do estudo dos seus oráculos contra as nações. Amós e Isaías julgam Israel, Judá e as demais nações em nome de normas morais que fazem parte da criação. Daí o seu carácter universal. É graças à observação da criação - a humanidade e o cosmos - que todos os seres humanos e todos os povos têm acesso ao conhecimento das normas morais. Se, em 
Am 3,9-10, lavé convoca a nobreza de Asdod e a do Egipto sobre os montes da Samaria para serem testemunhas das desordens, da opressão e da violência de que a cidade transborda, é porque elas conhecem as normas morais que regem Israel, as mesmas que regem os seus respectivos povos.

\section{Conclusões}

Para Amós e Isaías, como para os autores dos livros sapienciais, a ordem moral é a expressão da ordem do mundo tal como lavé a criou ou estabeleceu. Schmid demonstrou que, no Antigo Testamento, esses conceitos se expressam antes de mais pelo grupo lexical çdq (justiça), designando respectivamente a ordem do mundo (çèdèq) e o comportamento que com ela se conforma (çêāqāh) ${ }^{(29)}$. Barton demonstrou que as posições de Isaías no domínio da ética pressupõem o que em termos modernos se chamaria uma espécie de lei natu$\mathrm{ral}^{(30)}$. No meu estudo das intervenções de Isaías aquando da revolta de Judá contra a Assíria entre 705 e 701 a. C. cheguei à mesma conclusão ${ }^{(31)}$. A análise que precede mostra, a meu ver, que pode dizer-se outro tanto de Amós. Como Isaías, Amós fundamenta a moral numa espécie de lei natural. Aos olhos de ambos, não respeitar «a lei natural" é tentar subverter a ordem do mundo estabelecida por lavé. É pretender substituir a criação de lavé por outra da sua própria autoria. Em definitivo, é pretender usurpar as prerrogativas de lavé, o Criador do mundo e o seu Senhor. Para Amós e Isaías, tal pretensão é absurda e não pode senão fracassar. Aconteça o que acontecer, lavé será sempre o Criador, sem que as suas criaturas o possam destronar e, ainda menos, tomar o seu lugar. Quem tentar fazê-lo - Israel, Judá ou qualquer outro povo - atrairá infalivelmente sobre si a ruína. No caso de Israel e de Judá, Amós e Isaías imputam a responsabilidade unicamente aos governantes, mas a ruína atingirá também o povo, que será duplamente vítima dos seus dirigentes.

\section{Oseias e Jeremias}

Como Amós, Oseias exerceu a sua actividade no reino de Israel, na segunda metade do século VIII a. C. Jeremias exerceu a sua em Judá nos fins do século VII e nos princípios do século VI, sobretudo 
aquando dos acontecimentos relativos à conquista babilónica entre 597 e 587 a. C. Existem grandes afinidades entre Oseias e Jeremias. Os exegetas reconhecem geralmente que Jeremias depende de Oseias $^{(32)}$.

\section{Oseias}

Contrariamente ao livro de Amós e a Is 1-39, o livro de Oseias não tem oráculos contra as nações. É verdade que ele nomeia o Egipto treze vezes e a Assíria nove, mas não denuncia as suas práticas, não lhes pede contas nem Ihes anuncia qualquer infortúnio. O Egipto e a Assíria estão unicamente ao serviço das relações entre Israel e lavé.

O livro de Oseias está dominado pelas expressões religiosas das relações entre Israel e lavé, mas trata também dos seus aspectos morais $^{(33)}$. Os 4,1-2 é o texto mais pertinente para a questão do fundamento da mensagem moral de Oseias:

" Escutai a palavra de lavé, filhos de Israel, pois lavé tem um processo contra os habitantes do país,

${ }^{2}$ porque não há fidelidade nem amor, nem conhecimento de Deus no país.

Perjurar, mentir, matar, roubar

e cometer adultério propagam-se ${ }^{(34)}$,

e eles acrescentaram sangue derramado a sangue derramado."

Os 4,1-3 é o anúncio duma desgraça (v. 3) motivado (vv. 1-2). $\mathrm{O}$ autor dirige-se aos filhos de Israel, ordenando-lhes que escutem a palavra de lavé. Declara que lavé tem um processo contra os habitantes do país (v.1a) e expõe-lhes o seu objecto. Este tem duas vertentes: a inexistência de três qualidades e, como consequência, a existência de cinco acções. Não existe fidelidade/verdade, amor/bondade, nem conhecimento de Deus. As acções de que o país transborda expressam-se por meio de cinco infinitivos absolutos: perjurar, mentir, matar, roubar e cometer adultério. Os 4,1-2 é, assim, uma espécie de catálogo das acusações de carácter moral que a segunda parte do livro (Os 4-14) formula. É porventura da autoria não do próprio Oseias, mas de um dos editores do livro ${ }^{(35)}$. 
"Matar, roubar e cometer adultério" são três interditos do Decálogo (Ex 20,13-15; Dt 5,17-19). Os textos do Decálogo expressam-nos com os mesmos verbos e justapõem-nos, como Os 4,2. A única diferença reside na sua sequência. No Decálogo, o adultério encontra-se no centro, entre o assassínio e o roubo. Jb 24,14-15 menciona as três acções na mesma ordem que Os 4,2. Quanto ao sentido, "perjurar" e "mentir» correspondem a outros dois interditos do Decálogo, respectivamente a invocação do nome de Deus em vão e o falso testemunho (Ex 20,7.16; Dt 5,11.20). Os 4,2 documenta, assim, a existência de catálogos de interditos, que são os predecessores do Decálogo (Ex 20,1-17; Dt 5,6-21). Obra do próprio Oseias ou dum editor do livro, esse catálogo talvez seja o mais antigo que se conhece.

lavé acusa os habitantes do país de violar cinco ou três mandamentos. lavé era, por conseguinte, o garante da sua observância. Os 4,1-2 não diz explicitamente que lavé era também o seu autor, mas o contexto bíblico não deixa qualquer dúvida de que tal era o caso. Com efeito, o Decálogo é posto na boca de lavé (Ex 20,1-2; Dt 5,1.56). Dt 4,13 e 10,4 precisam que o próprio lavé o escreveu em duas tábuas de pedra. Oseias fundamenta, portanto, a moral em leis positivas que lavé deu directamente a Israel e só a ele. Assim se compreende que, no livro de Oseias, lavé não peça contas aos povos estrangeiros. Dado que não thes revelou as suas leis, lavé não os trata como sujeitos morais.

Em Os 4,1, os filhos de Israel são os espectadores do processo que lavé faz aos habitantes do país. Pensa-se de maneira praticamente unânime que as expressões "filhos de Israel» e "habitantes do país/ /terra” (yôx'béy hā'ārèç) são sinónimas. Que eu saiba, Simian-Yofre foi a única voz discordante. O autor baseia-se no sentido de yôxééy hā'ārèç no Antigo Testamento. Excepto numas quantas passagens recentes, onde a expressão designa os "habitantes da terra" no sentido universal(36), os yôxebéy hā'ârèç são os povos que precederam Israel no país de Canaã, isto é, os «Cananeus»(37). É o sentido adoptado por Simian-Yofre. lavé estaria em processo com os Cananeus, mas, de facto, dirigir-se-ia aos Israelitas «porque también ellos se han hecho solidarios con los cananeos»(38).

A expressão "habitantes do país" foi cunhada no contexto da lenda das origens egípcias de Israel. $O$ facto de essa lenda ocupar um lugar central no livro de Oseias aconselha a atribuir a "habitantes do país", em Os 4,1, o sentido habitual de Cananeus. Ora não é provável que existisse uma qualquer entidade étnica cananeia, distinta do resto 
da população, em Israel, no tempo de Oseias. Por maioria de razão, é improvável que ela existisse no reino de Judá, no tempo de um editor do livro bastante posterior. Por que razão o autor de Os 4,1 teria então usado a ficção dum processo de lavé contra um "povo" que já não existia? Não será mais natural que ele se refira a um grupo que existia realmente? Qual poderia ser esse grupo? O mais provável é que sejam os Israelitas que não partilhavam a ideia que Oseias tinha do iaveísmo. Contrariamente ao seu contemporâneo Amós, que não emite a mínima dúvida a respeito do carácter iaveísta das instituições nacionais de Israel - a monarquia e o culto $^{(39)}$-, Oseias considera-as baalistas $^{(40)}$ e rejeita-as em bloco.

Se as instituições de Israel são baalistas, aqueles que a elas aderem - a maioria da população do reino - não são iaveístas e, por conseguinte, também não são Israelitas ${ }^{(41)}$. Daí que Os 4,1 Ihes chame "habitantes do país". Ao fazê-lo, exclui-os de Israel e nega-lhes qualquer legitimidade. Os autores deuteronomistas fazem outro tanto. Nos seus escritos, os nomes dos antigos povos de Canaã são apodos dos seus concorrentes, isto é, dos compatriotas que não partilhavam as suas concepções do iaveísmo ${ }^{(42)}$. Os 4,1 opõe aos "habitantes do país" os "filhos de Israel», aqueles com quem o autor do texto se identifica $^{(43)}$. Os pecados de que o país transborda não seriam obra de Israelitas, mas de Cananeus que pretendem ser Israelitas.

\section{Jeremias}

O livro de Jeremias contém uma colectânea de oráculos contra as nações ${ }^{(44)}$, mas, contrariamente a Amós e a Is 1-39, não denuncia as suas injustiças. Reserva isso para Judá. Jr 7,9a é o texto mais pertinente para o nosso propósito. O texto acusa os habitantes de Jerusalém de

“... roubar, matar, cometer adultério, fazer juramentos falsos..."

Este versículo faz parte de $\mathrm{Jr} 7,1-15^{\star}$, a que se chama habitualmente a primeira versão do "sermão do Templo". Os exegetas distinguem nela dois estratos literários e teológicos. A autoria jeremiana do mais antigo é geralmente reconhecida. O mais recente seria fruto duma redacção deuteronomista ou aparentada ${ }^{(45)}$. Na opinião da maioria dos exegetas, o texto primitivo tinha por tema central o templo, 
denunciava a falsa segurança fundada na crença na sua inviolabilidade (vv. 4.10-13.14) e referia só os pecados de índole social mencionados no v. 9a. Esse versículo contém quatro acusações formuladas, como em Os 4,2, por meio de verbos no infinitivo absoluto. As três primeiras são idênticas às de Os 4,2. Correspondem a três interditos que estão igualmente justapostos no Decálogo (Ex 20,13-15; Dt 5, 17-19). Os 4,2, Jr 7,9a e o Decálogo enumeram os três mandamentos numa ordem diferente. A quarta acusação "fazer juramentos falsos" corresponde ao interdito do falso testemunho, que segue imediatamente os outros três no Decálogo (Ex 20,16 / Dt 5,20). Como Oseias, Jeremias fundamenta, assim, a moral nas leis positivas que lavé deu directamente ao seu povo e só a ele se aplicam.

\section{Conclusões}

Todos os profetas bíblicos vêem em lavé a fonte da moral, bem como o autor das regras da moralidade e o garante do seu respeito. Para eles, a moral é, assim, uma realidade teológica. No entanto, os profetas divergem em relação às pessoas a quem lavé revela as regras morais e aos meios de que se serve para isso. Segundo uns, lavé revela-as indirectamente, por meio da criação ou da ordem do mundo - humano e cósmico - a todos os seres humanos e a todos os povos. Todos eles podem induzir as normas morais mediante a observação do mundo: do ser humano, da sociedade e do cosmos. Por isso, as normas morais têm valor universal. Aplicam-se a todos os seres humanos e a todos os povos. lavé vela pelo respeito das ditas normas, medindo com elas o comportamento de todos os seres humanos e de todos os povos. Segundo outros profetas, lavé revela as regras morais a Israel apenas. Fá-lo mediante leis positivas, que ele dita directa e exclusivamente a Israel, o seu povo. Essas leis só se aplicam a Israel e só valem para ele ${ }^{(46)}$.

As duas concepções dos fundamentos da moral que acabo de resumir não são apanágio exclusivo dos profetas. Encontram-se também no resto do Antigo Testamento. De facto, fazem parte de dois sistemas religiosos, isto é, de duas formas do iaveísmo ou de duas religiões de lavé(47). Uma funda-se no mito da criação, representa lavé sob a imagem do rei - o rei do universo graças à sua vitória contra o Caos - e concerne todos os seres humanos e todos os povos, aos quais lavé se revela por meio da cultura e da natureza. Poderia cha- 
mar-se o iaveísmo cósmico. É a variante hebraica da koiné religiosa do antigo mundo semita. Representado por Amós e Isaías, este iaveísmo é o único que está documentado nos livros sapienciais mais antigos (Provérbios, Job e Qohelet ou Eclesiastes) e num grande número de salmos, sobretudo os chamados salmos reais. É a forma de iaveísmo mais antiga. Tem por centro a realeza, que foi o coração das instituições dos reinos de Israel e de Judá. O rei humano era o agente de lavé na manutenção da criação, da justiça ou da ordem do mundo - neste contexto, as três expressões são praticamente sinónimas. O iaveísmo fundado na criação foi sempre a religião oficial do reino de Israel. Tudo indica que ele foi o único que existiu no reino de Judá até finais do século VIII a. C., e continuou a ser a sua religião oficial pelo menos enquanto existiu a monarquia.

A outra forma do iaveísmo funda-se na história das relações entre lavé e Israel. Poderia chamar-se o iaveísmo histórico. Representa lavé sob as imagens do Pai e do Esposo de Israel ou do Soberano que the concede a sua Aliança. lavé revela-se directa e exclusivamente a Israel. Sobretudo, dita-lhe leis que só a ele se aplicam. O representante mais antigo deste iaveísmo que se pode datar com uma certeza razoável é Oseias, em Israel. O Deuteronómio e Jeremias, nos fins do século VII a. C. são os seus primeiros representantes datáveis no reino de Judá. Foi igualmente adoptado pelos círculos sacerdotais de Jerusalém. Este iaveísmo põe amiúde as leis, concretamente as leis de carácter moral, em relação com o êxodo do Egipto, o acontecimento fundador das relações entre Israel e lavé e que constituiu Israel como povo, o povo de lavé. Por exemplo, Dt 15,12-18 justifica a lei relativa à alforria dos escravos hebreus no sétimo ano pela libertação de Israel do Egipto. De maneira semelhante, Ex 22,20 justifica a proibição da opressão dos estrangeiros pelo facto de que Israel também foi estrangeiro no Egipto. O caso dos pesos e das medidas é particularmente interessante a este respeito. Para os Provérbios, que insistem muito nisso, os pesos e as medidas justos são obra de lavé. Fazem parte da criação ou da ordem do mundo. Qualquer ser humano os pode conhecer e deve respeitar. Não o fazer é uma abominação para lavé ( $\operatorname{Pr} 11,1 ; 20,10.23)$. Pelo contrário, em Lv 19,35-36, os pesos e as medidas são objecto de leis positivas que lavé dita a Israel apenas. lavé proíbe a fraude nos pesos e nas medidas e ordena o uso de pesos e medidas justos, fundando as suas ordens na autoridade que Ihe confere o facto de ter feito sair Israel do Egipto.

Os dois iaveísmos estiveram em concorrência renhida durante séculos, mas acabaram por fundir-se. Relativamente às expressões 
morais, as normas de conduta do iaveísmo cósmico coincidiam com frequência com as leis do iaveísmo histórico. Enquanto o primeiro propunha as suas normas de conduta a todos os seres humanos em nome da ordem do mundo - a justiça - estabelecida pelo Criador, o segundo ditava as suas leis a Israel - e exclusivamente a ele - em nome da sua relação especial com lavé. Identificando explicitamente a Sabedoria com a Lei de Moisés, o livro conhecido pelos nomes de Eclesiástico, Ben Sirá ou Sirácide, escrito por Jesus ben Sirá nos começos do século II a. C., é porventura o primeiro testemunho da fusão das expressões morais, e não só, dos dois iaveísmos (Ecl 24,23)(48).

\section{Notas}

(1) Francolino J. GONÇALVES, "Les "Prophètes Écrivains" étaient-ils des nebîîim?», in P. M. M. DAVIAU, J. W. WEVERS and M. WEIGL (eds), The World of the Aramaeans. I. Biblical Studies in Honour of Paul-Eugène Dion (JSOT.S 324), Sheffield, Sheffield Academic Press, 2001, pp. 144-185.

(2) Um dos estudos mais recentes e completos sobre a questão é Walter J. HOUSTON, Contending for Justice. Ideologies and Theologies of Social Justice in the Old Testament (LHB / OTS 428), London-New York, T \& T Clark, 2006.

(3) Veja-se, por exemplo, Abraham KUENEN, The Prophets and Prophecy in Israel. An Historical and Critical Enquiry With an Introduction by John Muir, London, 1877; Reimpresso: Amsterdam, Philo Press, 1969, p. 585; Ernest RENAN, Histoire du Peuple d'Israël, II, Paris, Calman Lévy, 1891, pp. 273-274.

(4) Para a tradição judaica, a Torá é também a parte mais importante das Escrituras.

(5) Is 13-23; JrLXX 25,14-31,44; Ez 25-32; Sf 2,4-15.

(6) Existe uma abundante bibliografia sobre os oráculos de Amós contra as nações estrangeiras. Os estudos de Barton são os mais pertinentes para o nosso propósito: John BARTON, Amos's Oracles against the Nations. A study of Amos 1.3-2.5 (The Society for Old Testament Study. Monograph Series 6) Cambridge, Cambridge University Press, 1980; IDEM., Ethics in the Old Testament. The 1997 Diocese of British Columbia John Albert Hall Lectures at the Centre for Studies in Religion and Society in the University of Victoria, Harrisburg, PA, Trinity Press International, 1998, pp. 61-63.

(7) Pode dizer-se outro tanto dos crimes de que os oráculos secundários acusam Tiro/ /Fenícia $(1,9-10)$ e Edom (1,11-12). A única excepção é o oráculo contra Judá que denuncia pecados de ordem religiosa (2,4-5).

(8) Em Mi 4,12-13, o próprio lavé ordena a Sião que esmague numerosos povos em termos semelhantes.

(9) Prática várias vezes mencionada no Antigo Testamento (2 R 8,12; 15,16 e Os 14,1). Contestando a compreensão tradicional, já documentada pela Setenta, Cohen vê em hārôt não o plural do adjectivo feminino hārāh (grávida), mas uma forma irregular do plural do substantivo har (montanha), e traduz: «... porque cortaram/separaram ('al- biq ${ }^{\circ} a \bar{m}$ ) as montanhas de Galaad para aumentar o seu território...". O único crime de Amon seria o 
facto de ter aumentado o seu território anexando territórios pertencentes a outro povo; Chaim COHEN, "Two Misunderstood Verses in the Latter Prophets: Jer 9:24, Amos 1:13", in Y. SEFATI et al. (eds), "An Experienced Scribe Who Neglects Nothing": Ancient Near Eastern Studies in Honor of Jacob Klein, Bethesda, MD, CDL Press, 2005, pp. 695-706 (685-706).

(10) Is $5,8.11 .18 .20 .21 .22 ; 10,1 ; 29,15 ; 30.1 ; 31,1 ; 33,1$.

(11) Em Is 18,1, é usada em relaçāo com o Egipto.

(12) Dt 32,8-9; cf. também Dt 29,25; Is 63,17 ; Jr 3,19; 10,16; 12,7-10; Za 2,16; Ps 74,2.17; 78,71; Hans WILDBERGER, Jesaja. I. Teilband. Jesaja 1-12 ( BK X/1), Neukirchen-Vluyn, Neukirchener Verlag, 1972, pp. 399-400; Siegfried MITTMANN, “"Wehe! Assur, Stab meines Zorns" (Jes 10,5-9.13ab-15", in V. FRITZ et al. (eds), Prophet und Prophetenbuch. Festschrift für Otto Kaiser (BZAW 185), Berlin-New York, Walter de Gruyter, 1989, p. 120 (111-132).

(13) Is 1,21 ; cf. Ex 20,13 .

(14) Am 2,6b; 8,6a; cf. Ex 21,2-11; Dt 15,12-18 e Lv 25,39-42.

(15) Is 1,23 ; cf. Ex 20,15 .

(16) Am 8,5; cf. Dt 25,13-15 e Lv 19,35-36.

(17) Am 2,8a; cf. Ex 22,25-26 e Dt 24,12-13.17.

(18) Am 5,7.10-12; Is 1,23; 5,23; cf. Ex 23,1-3.6-8 e Dt 10,17; 16,19; 27,25.

(19) Is 1,17.23; cf. Ex 22,20-23; Dt 24,17-18; $27,19$.

(20) No que diz respeito a Amós, veja-se P.-E. DION, "Le message moral du prophète Amos s'inspirait-il du droit de l'alliance?", Science et Esprit 27 (1975) 5-34.

(21) Am $4,1-3 ; 6,1-7$, Is $5,11-13.22-23 ; 28,1-3.7-13$.

(22) Am 2,8; 4,4-5; 5,4-5.21-24; Is 1,10-17.

(23) Francolino J. GONÇALVES, "Comer y beber en los oráculos de Isaías. Aporte al tema "Isaías y la sabiduria", in R. LÓPEZ ROSAS (ed.), Comer, beber y alegrarse. Estudios bíblicos en honor a Raúl Duarte Castillo (Estudios Bíblicos Mexicanos 1), México, D. F., Qol y Departamento de Publicaciones de la Universidad Pontificia de México, 2004, pp. 61-88 (53-88).

(24) Traduzo assim xāgāh $b^{-}$, em relação com o vinho (yayin) e a bebida inebriante (xékār).

(25) Para uma análise de Is 28,7-13, veja-se Francolino J. GONÇALVES, L'expédition de Sennachérib en Palestine dans la littérature hébraïque ancienne (ÉB, NS 7), Paris, Gabalda, 1986, pp. 187-195.

(26) Ez 44,21 refere-se ao culto do templo futuro.

(27) É o que parece pressupor o Texto Massorético de Mi 2,11 (não a Setenta), Jr 35,1-6 e Act 2,13. O uso de bebidas para provocar a revelação está documentado em Mari, mas não se sabe ao certo se essas bebidas eram ou não alcoólicas; veja-se Jean-Marie DURAND, Archives épistolaires de Mari I/1 (ARM 26), Paris, Éditions Recherche sur les Civilisations, 1988, nn. 207 e 212 (pp. 435-437 e 440-441); Francisco CARAMELO, A linguagem profética na Mesopotâmia (Mari e Assíria) (Patrimonia Historica. Estudos), Cascais, 2002, pp. 71-75 e 84-86; Martti NISSINEN, Prophets and Prophecy in the Ancient Near East (Writings from the Ancient World 12), Atlanta, SBL, 2003, nn. 17 e 22 (pp. 39-41 e 46-47). 
(28) As duas traduções são possíveis. Segundo a divisão massorética do texto, o verbo lavrar não tem complemento directo explícito. Os autores que aceitam essa divisão pensam que o complemento directo é "rochedo", o substantivo que precede. Outros dividem o texto de maneira diferente: babbāqār yām em vez de babbeqaārîm. Nesse caso, lavrar tem explicitamente yām (mar) como complemento directo. Seja qual for a leitura que se adopte, o texto refere-se a uma acção absurda.

(29) Hans Heinrich SCHMID, Gerechtigkeit als Weltordnung. Hintergrund und Geschichte des alttestamentlichen Gerechtigkeitsbegriffes (Beiträge zur Historischen Theologie 40), Tübingen, J. C. B. MOHR (Paul Siebeck), 1968; IDEM, «Schöpfung, Gerechtigkeit und Heil. "Schöpfungstheologie“ als Gesamthorizont biblischer Theologie”, ZThK 70 (1973) 1-19.

(30) John BARTON, "Ethics in Isaiah of Jerusalem", JTS 32 (1981) 1-18; IDEM, Isaiah 1-39, Sheffield, Sheffield Academic Press, 1995, pp. 55-62; IDEM, "Ethics in the Book of Isaiah", in C. C. BROYLES and C. A. EVANS (eds), Writing and Reading the Scroll of Isaiah. Studies of an Interpretive Tradition (VTS 70/1 - Formation and Interpretation of Old Testament Literature 1/1), Leiden-New York-Köln, Brill, 1997, pp. 67-77; IDEM, Ethics in the Old Testament (supra n. 6), pp. 63-65. Cf. também H. G. M. WILLIAMSON, "Isaiah and the Wise", in J. DAY et al. (eds), Wisdom in Ancient Israel. Essays in honour of J.A. Emerton, Cambridge, Cambridge University Press, 1995, pp. 137-141 (133-141).

(31) Francolino J. GONÇALVES, L'expédition de Sennachérib (supra n. 25 ), sobretudo pp. 265-269.

(32) J. JEREMIAS, “Hoseas Einfluss auf das Jeremiabuch - ein traditionsgeschichtliches Problem", in K.A. TÅNGBERG (ed.), Text and Theology: Studies in Honour of Professor Dr Theol. Magne Saebo, Oslo, Verbum, 1994, pp. 112-134; M. SCHULZ-RAUCH, Hosea und Jeremia: Zur Wirkungsgeschichte des Hoseabuches (Calwer theologische Monographien A, Bibelwissenschaft 16), Stuttgart, Calwer Verlag, 1996; H. LALLEMAN-DE WINKEL, Jeremiah in Prophetic Tradition. An Examination of the Book of Jeremiah in the Light of Israel's Prophetic Traditions (Contributions to Biblical Exegesis \& Theology 26), Leuven, Peeters, 2000; Silvana MANFREDI, Geremia in Dialogo: Nessi con le tradizioni profetiche e originalità in Ger 4,5-6,30, Roma, Salvatore Sciascia Editore, 2002, pp. 331-341.

(33) Os $4,1-3 ; 6,7-10 ; 7,1-2 ; 10,4$.

(34) Sem ter em conta a pontuação massorética, vejo nos cinco infinitivos o sujeito de pārāçû, com o sentido de "jorrar, transbordar, propagar-se, crescer", como no v. 10, onde se lê a única outra ocorrência desse verbo no livro de Oseias; A. A. MACINTOSH, Hosea (ICC), Edinburgh, T \& T Clark, 1997, pp. 129-130.

(35) Sebastian GRÄTZ, "Die vergebliche Suche nach Gott. Traditions- und kompositionsgeschichtliche Überlegungen zu Herkunft und Funktion der Strafvorstellungen in Hosea iv 1-vi 6", VT 50 (2000), pp. 201-202 (200-217).

(36) Jr 25,29.30; So 1,18 ( ?); Za 11,6; Ps 33,14.

(37) Gn 36,20; Ex 23,31; Nb 32,17; 33,52.55; Jos 2,9.24; 7,9; 9,11.24; 13,21; Jg 1,33; 2,2; 1 Ch 11,$4 ; 22,18$. Em Jr 1,14; 6,12; 10,18 e 13,13, a expressão designa os Judaítas, mas sugere a sua assimilação aos Cananeus; cf. também Jl 1,2.14 e 2,1.

(36) Horacio SIMIAN-YOFRE, El desierto de los dioses. Teología e Historia en el libro de Oseas, Córdoba, Ediciones el Almendro, 1993, p. 65.

(39) É verdade que Amós condena o culto israelita, mas não o faz por pensar que ele não tem lavé por objecto. O próprio lavé rejeita o culto que Israel lhe presta porque anda associado à injustiça, quando não se alimenta dela. 
(40) Sobre o sentido desta acusação, veja-se Jörg JEREMIAS, “Der Begriff „Baal“ im Hoseabuch und seine Wirkungsgeschichte", in W. DIETRICH / M. KLOPFENSTEIN (eds), Ein Gott allein? JHWH-Verehrung und biblischer Monotheismus im Kontext der israelitischen und altorientalischen Religionsgeschichte (ОВО 139), Freiburg Schweiz, Universitätsverlag/Göttingen, Vandenhoeck \& Ruprecht, 1994, pp. 441-462; J. A. DEARMAN "Interpreting the Religious Polemics Against Baal and the Baalim in the Book of Hosea", OTE 14 (2001) 9-25; Lyn M. BECHTEL, "The Metaphors of "Canaanite" and "Baal" in Hosea" in J. KALTNER and L. STULMAN (eds), Inspired Speech: Prophecy in the Ancient Near East. Essays in Honor of Herbert B. Huffmon (JSOT.S 378), London-New York, T \& T Clark, 2004, pp. 203-215.

(41) Segundo os critérios de Oseias, Amós não era iaveísta nem Israelita.

(42) Robert L. COHN, "The Second Coming of Moses: Deuteronomy and the Construction of Israelite Identity", in R. MARGOLIN (ed.), Proceedings of the Twelfth World Congress of Jewish Studies, Jerusalem, July 29 - August 5, 1997. Division A. The Bible and Its World,

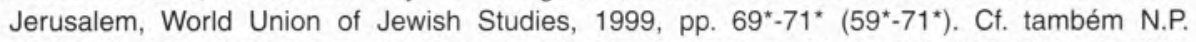
LEMCHE, The Canaanites and Their Land. The Tradition of the Canaanites (JSOT.S 110), Sheffield, Sheffield Academic Press, 1991, pp. 162-169; A.D.H. MAYES, "Deuteronomistic Ideology and the Theology of the Old Testament", JSOT 82 (1999) 78-79 (57-82); Lyn M. Bechtel, "The Metaphors of "Canaanite" and "Baal" in Hosea" (supra, n. 40), pp. 203-215.

(43) Os 12,8-9 documenta provavelmente a mesma oposição.

(44) JrLXX 25,14-31,44 / JrTM 46-51.

(45) Francolino J. GONÇALVES, "LLa maison qui est appelée du nom du Seigneur", au livre de Jérémie", in J.-C. PETIT (ed.), "Où demeures-tu?". La maison depuis le monde biblique. En hommage au professeur Guy Couturier, Montréal, Fides, 1994, pp. 165-185. Mais longo do que a Setenta, o Texto Massorético talvez documente um terceiro estrato; veja-se a minha recensão de P. C. CRAIGIE et al., Jeremiah 1-25 (WBC 26), Dallas, Texas, Word Books, 1991, na RB 107 (2000) 107-109 (105-110).

(46) O sentido do nome Israel mudou no decurso dos séculos. Na origem designava o reino de que Israel foi um dos nomes. Depois designou o reino de Judá e, sobretudo, o grupo daqueles que se consideravam como sendo os fiéis de lavé.

(47) Francolino J. GONÇALVES, "Yahvé, su pueblo y los demás pueblos en el Antiguo Testamento", in G. TEJERINA ARIAS (ed.), Radicalidad evangélica y fundamentalismos religiosos (Bibliotheca Salmanticensis. Estudios 256), Salamanca, Publicaciones Universidad Pontificia, 2003, pp. 135-165; IDEM, "Mundos bíblicos", Cadernos ISTA 18 (2005) 7-34.

(48) Texto retocado de uma conferência proferida no dia 16 de Abril de 2008 no Centro de História da Faculdade de Letras da Universidade de Lisboa. 